\title{
Hybrid Polymer-Immobilized Nanosized Pd Catalysts for Hydrogenation Reaction Obtained via Frontal Polymerization
}

\author{
Anatolii D. Pomogailo and Gulzhian I. Dzhardimalieva \\ Institute of Problems of Chemical Physics, Russian Academy of Sciences, Chernogolovka 142432, \\ Academician Semenov Avenue, 1, Russia \\ Correspondence should be addressed to Anatolii D. Pomogailo; adpomog@icp.ac.ru
}

Received 27 August 2012; Accepted 2 November 2012

Academic Editor: Mohammed M. Bettahar

Copyright (C) 2013 A. D. Pomogailo and G. I. Dzhardimalieva. This is an open access article distributed under the Creative Commons Attribution License, which permits unrestricted use, distribution, and reproduction in any medium, provided the original work is properly cited.

\begin{abstract}
A new approach to the synthesis of mixed-type immobilized catalysts by frontal polymerization of metal-containing monomer in the presence of highly dispersed mineral support has been developed. Synthesis of the acrylamide Pd(II) nitrate complex, $\mathrm{Pd}\left(\mathrm{CH}_{2}=\mathrm{CHCONH}_{2}\right)_{2}\left(\mathrm{NO}_{3}\right)_{2}(\mathrm{PdAAm})$, on the $\mathrm{SiO}_{2}\left(\mathrm{Al}_{2} \mathrm{O}_{3}, \mathrm{C}\right)$ surface and its consequent frontal polymerization and reduction lead to the formation of organic-inorganic composites with polymer-stabilized Pd nanoparticles. The immobilized metal complexes and palladium nanoparticles were characterized by various physical and chemical methods. The synthesized hybrid nanocomposites are efficient and selective catalysts for hydrogenation of cyclohexene, alkene, and acetylene alcohols, as well as diand trinitrotoluene. Catalyst intermediates separated by nondestructive testing method have been described and changing in the palladium charge during the catalytic process has been identified.
\end{abstract}

\section{Introduction}

In recent years materials containing metal nanoparticles were intensively studied specially as catalysts due to their unique physical and chemical properties [1], high ratio of surface atoms to the total number of atoms in a particle, and possibility to vary catalytic properties by controlling the size of particles [2-4]. Zero-valent palladium complexes and nanoparticles are well known as efficient and selective catalysts for many organic reactions such as alkene arylation $[5,6]$, cross-coupling [7], hydrogenation of dienes, olefins $[8,9]$, and unsaturated alcohols [10]. Liquid phase catalytic hydrogenation of aromatic nitro compounds is widely used to produce corresponding amino derivatives, which are intermediates in the production of plastics, pharmaceuticals, and so forth. Hydrogenation of trinitrotoluene (TNT) in recent years becomes a reaction of practical importance for utilization of nitroaromatic explosives to useful chemicals (dyes, amino compounds, etc.) $[11,12]$. Platinum metals catalyze selective reduction of nitroaromatic compounds. Particular attention is paid to developing effective and selective palladium catalysts based on complexes and nanoparticles [1316]. Aggregation and agglomeration of nanoparticles limits their use as catalysts, so they are fixed on supports (metal oxides, zeolites, carbon, etc.) or stabilized with different types of ligands, including polymers. One of the promising methods to obtain metal polymers is a polymer-mediated synthesis based on in situ poly- and copolymerization of metal-containing monomers with subsequent controlled thermolysis of the resulting products. This approach allows one to combine the formation of metal nanoparticles and stabilizing polymer shells in one stage $[17,18]$.

The aim of this paper is to demonstrate a new approach to the design of catalysts by the frontal polymerization of acrylamide $\mathrm{Pd}(\mathrm{II})$ nitrate complex on inorganic supports and to characterize the features of their catalytic properties in reactions of hydrogenation of various unsaturated compounds (cyclohexene, olefinic and acetylenic alcohols and selective reduction of di-and trinitrotoluene). 


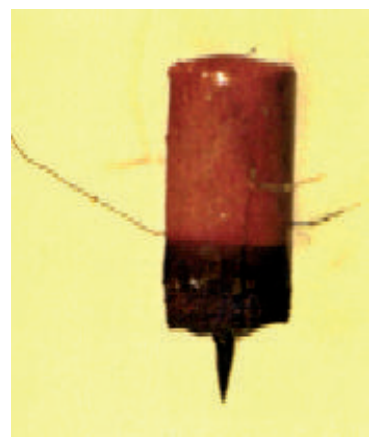

$t=20 \mathrm{~s}$

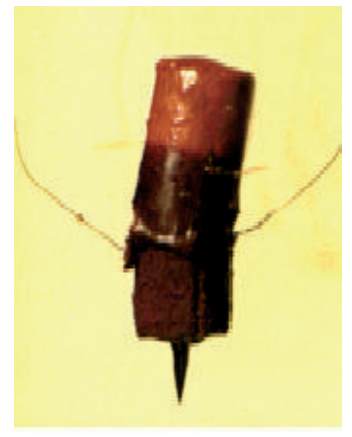

$t=45 \mathrm{~s}$

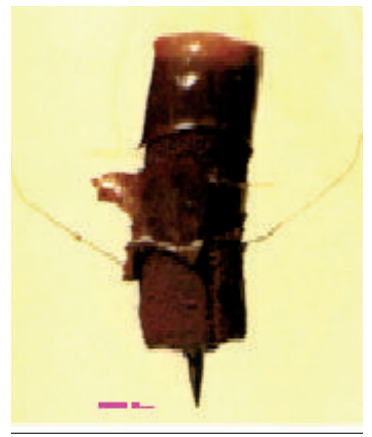

$t=55 \mathrm{~s}$

FIGURE 1: Photomontage of polymerization front propagation of metal nitrate acrylamide complex.

N1s

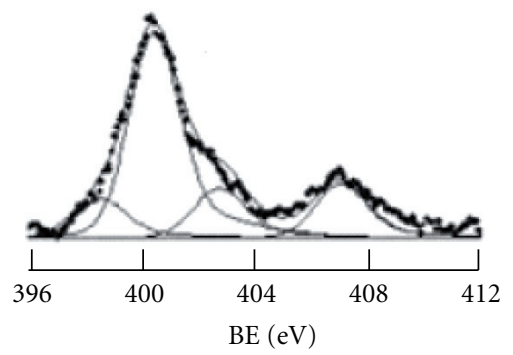

N1s

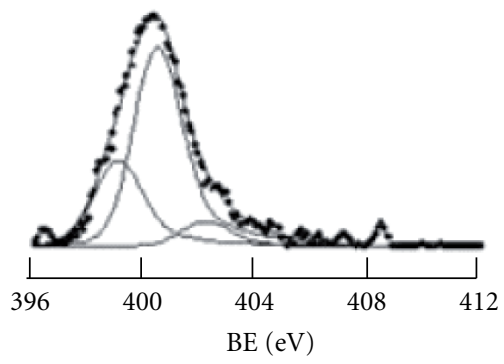

N1s

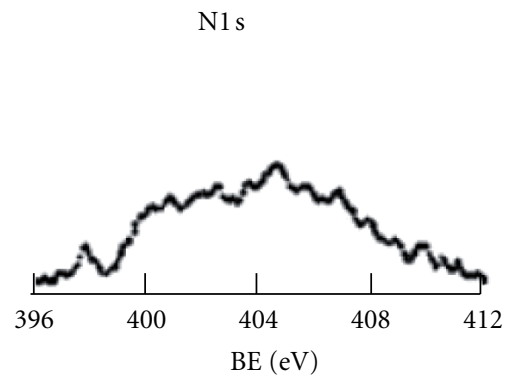

Pd3d

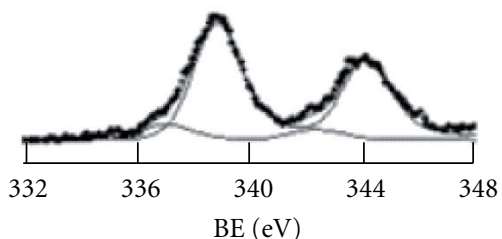

(a)

(b)
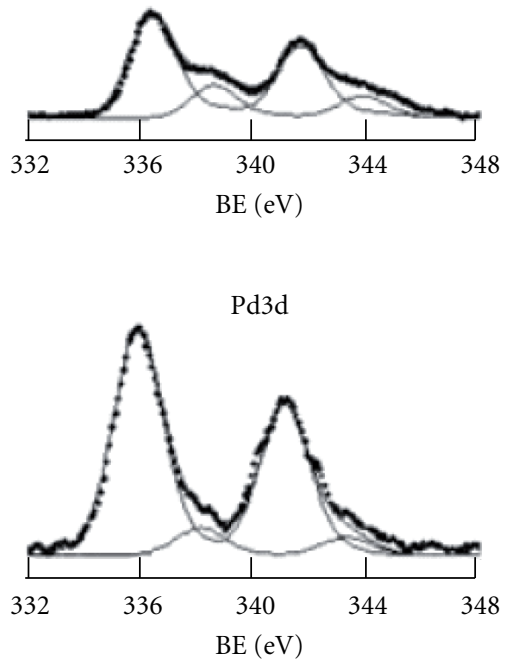

(c)

Figure 2: XPS spectra of (a) acrylamide complex monomer with $\mathrm{Pd}\left(\mathrm{NO}_{3}\right)_{2}$, (b) PdAAm after polymerization, and (c) the same after cyclohexene hydrogenation. 
TABLE 1: Elemental analysis of the acrylamide complexes of Pd(II) nitrate and the relative content of elements according to the XPS data.

\begin{tabular}{|c|c|c|c|c|c|c|c|c|}
\hline \multirow{2}{*}{ Complex } & \multicolumn{4}{|c|}{ Found/calculated, wt.\% } & \multicolumn{4}{|c|}{ Relative concentration, at.\% } \\
\hline & $\mathrm{C}$ & $\mathrm{H}$ & $\mathrm{N}$ & $\mathrm{Pd}$ & $\mathrm{C}$ & $\mathrm{O}$ & $\mathrm{N}$ & $\mathrm{Pd}$ \\
\hline $\mathrm{Pd}\left(\mathrm{NO}_{3}\right)_{2}$ & - & $1,4 / 1,5$ & $10,2 / 10,5$ & $40,4 / 39,9$ & & 68 & 21 & 10,5 \\
\hline PdAAm & 20.1/19.4 & $3,5 / 2.7$ & $15,1 / 15,0$ & $29,4 / 28,6$ & 52 & 27 & 19 & 2 \\
\hline $\mathrm{PdAAm} / \mathrm{SiO}_{2}$ & - & - & - & 5.2 & 16 & 57 & 6 & 0.7 \\
\hline $\mathrm{PdAAm} / \mathrm{C}$ & - & - & - & 10.2 & 83 & 14 & 2.8 & 0.2 \\
\hline
\end{tabular}

TABLE 2: Results of the XPS, XRD, and TEM analysis of polymer hybrid nanocomposites based on PdAAm.

\begin{tabular}{lcc}
\hline Nanocomposite & ${\mathrm{Pd} 3 \mathrm{~d}_{5 / 2} / \mathrm{eV}}$ & Particle size of $\mathrm{Pd}, \mathrm{nm}$ \\
\hline PdAAm & $336.5,338.9$ & 3.9 \\
PdAAm $/ \mathrm{SiO}_{2}$ & $337.6,338.9$ & $3.6-4$ \\
PdAAm $/ \mathrm{Al}_{2} \mathrm{O}_{3}$ & - & 4 \\
PdAAm $/ \mathrm{C}$ & $338.5,341.3$ & 8 \\
\hline
\end{tabular}

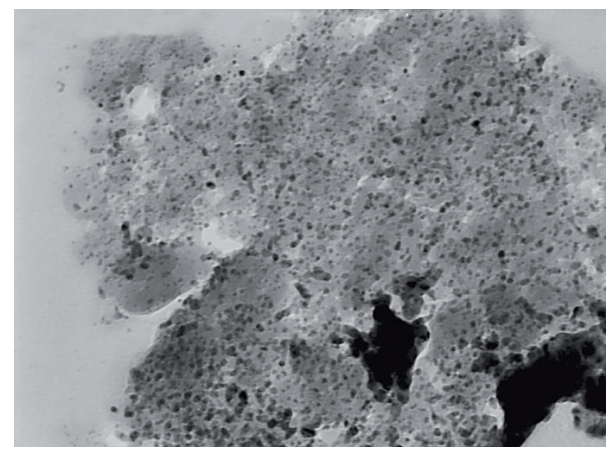

FIGURE 3: Electron micrograph of poly-PdAAm/SiO ${ }_{2}$ (magnification of 125000x).

\section{Experimental}

2.1. Reactants. Benzene and diethyl ether (chemically pure grade) were purified by standard methods. Methanol, $\mathrm{PdCl}_{2} \cdot 4 \mathrm{H}_{2} \mathrm{O}$, acrylamide (AAm) (Fluke), and toluene were used without additional purification. Allyl alcohol (99\%, Reanal Budapest) was distilled at atmospheric pressure and the main fraction was collected at bp. $96^{\circ} \mathrm{C} .3,7,11,15-$ Tetramethylhexadecine-1-ol-3 ( $\mathrm{C}_{20}$ acetylenic alcohol) was purified by double distillation and the purity was checked chromatographically. Concentrated $\mathrm{HNO}_{3}\left(\rho=1.18 \mathrm{~g} / \mathrm{cm}^{3}\right)$ was distilled at atmospheric pressure; the main fraction was collected at bp. $110^{\circ} \mathrm{C}$. Silica gel 60 (220-240 mesh, specific area $S_{\text {spec. }}=240 \mathrm{~m}^{2} / \mathrm{g}$, Lancaster), carbon black $\left(S_{\text {spec. }}=850 \mathrm{~m}^{2} / \mathrm{g}\right)$, and $\mathrm{Al}_{2} \mathrm{O}_{3}\left(S_{\text {spec. }}=123 \mathrm{~m}^{2} / \mathrm{g}\right)$ were used as inorganic supports. The supports were preactivated (calcination and evacuation at $450^{\circ} \mathrm{C}$ ) and cooled in an inert atmosphere.

2.2. Synthesis of $\mathrm{Pd}\left(\mathrm{NO}_{3}\right)_{2} \cdot 2 \mathrm{H}_{2} \mathrm{O}$. $\mathrm{Pd}(\mathrm{II})$ nitrate was synthesized by the interaction of freshly distilled $\mathrm{HNO}_{3}$ and freshly precipitated palladium hydroxide $\left(2.6 \mathrm{~g}, 1.84 \cdot 10^{-2} \mathrm{~mol}\right.$.) obtained by the treatment of $\mathrm{Na}_{2} \mathrm{PdCl}_{4}$ complex salt $(5.5 \mathrm{~g}$, $1.84 \cdot 10^{-2}$ mol.) with sodium hydroxide. Found (\%): N, 10.2; H, 1.4; Pd, 40.4. Calculated (\%): N, 10.5; H, 1.5; Pd, 39.9. IR spectrum (tablets with $\mathrm{KBr}), v / \mathrm{cm}^{-1}: 850,1386\left(\mathrm{NO}_{3}\right), 1650$. XPS, eV: $\mathrm{Pd} 3 \mathrm{~d}_{5 / 2}=338.8, \mathrm{~N} 1 \mathrm{~s}=407.2, \mathrm{O} 1 \mathrm{~s}=532.8$.

2.3. Synthesis of $\mathrm{Pd}\left(\mathrm{CH}_{2}=\mathrm{CHCONH}_{2}\right)_{2}\left(\mathrm{NO}_{3}\right)_{2}$ (PdAAm). PdAAm metal monomer was synthesized by a modified method for preparation of acrylamide complexes of transition metal nitrates [19]. Pd(II) nitrate and acrylamide were mixed in a molar ratio of 1:5 in an inert atmosphere and ground into paste-like consistency, then washed with dry ether and dried in vacuum to constant weight. Found (\%): C, 20.1; N, 15.1; H, 3.5; Pd, 29.4. Calculated (\%): C, 19.4; N, 15.0; H, 2.7; $\mathrm{Pd}, 28.6$. IR spectrum (tablets with $\mathrm{KBr}), v / \mathrm{cm}^{-1}$ : $3190\left(v_{\mathrm{s}} \mathrm{NH}\right), 3428\left(\nu_{\mathrm{as}} \mathrm{NH}\right), 1665(\mathrm{C}=\mathrm{O}), 1384\left(\mathrm{NO}_{3}\right)$.

2.4. Synthesis of PdAAm in the Presence of an Inorganic Support. PdAAm in the presence of $\mathrm{SiO}_{2}$ or $\mathrm{Al}_{2} \mathrm{O}_{3}$ or $\mathrm{C}$ was synthesized by the method mentioned above. Calculated content of $\mathrm{Pd}$ is $5-10 \mathrm{wt} . \% / \mathrm{g}$ in the mixed type catalyst (polymer + inorganic support). In a typical procedure a mixture of calculated amounts of $\mathrm{Pd}(\mathrm{II})$ nitrate, acrylamide, and $\mathrm{SiO}_{2}\left(\mathrm{Al}_{2} \mathrm{O}_{3}\right.$, or $\left.\mathrm{C}\right)$ were ground into paste-like state in an agate mortar inside a box with an inert atmosphere, then washed with benzene, ether, and dried in a vacuum during 12 hours at $30^{\circ} \mathrm{C}$. The content of $\mathrm{Pd}$ (wt\%) was 5.2 $\left(\mathrm{PdAAm} / \mathrm{SiO}_{2}\right)$, $8.9\left(\mathrm{PdAAm} / \mathrm{Al}_{2} \mathrm{O}_{3}\right)$, and $10.2(\mathrm{PdAAm} / \mathrm{C})$.

2.5. Preparation of $P d / C$. Standard $\mathrm{Pd} / \mathrm{C}$ catalyst (for comparison) was synthesized by impregnation of activated carbon with a calculated amount of aqueous solution of $\mathrm{Na}_{2} \mathrm{PdCl}_{4}$ prepared by boiling a mixture of $\mathrm{PdCl}_{2}$, water, and concentrated $\mathrm{HCl}$ during 2 hours, then was washed and reduced by $\mathrm{NaBH}_{4}$ at $40^{\circ} \mathrm{C}$ and additionally heated for 15 minutes at $80^{\circ} \mathrm{C}$. The resulting catalyst was filtered and washed with distilled $\mathrm{H}_{2} \mathrm{O}$, then dried at $110^{\circ} \mathrm{C}$ during 3-5 hour. The content of Pd was 5 wt.\%.

2.6. Frontal Polymerization of $\mathrm{PdAAm}$ and $\mathrm{PdAAm} / \mathrm{SiO}_{2}$ $\left(\mathrm{Al}_{2} \mathrm{O}_{3}, \mathrm{C}\right)$. To carry out frontal polymerization (FP) the sample of prepared PdAAm or PdAAm $/ \mathrm{SiO}_{2}\left(\mathrm{Al}_{2} \mathrm{O}_{3}, \mathrm{C}\right)$ was prepressed into tablets with $0.5-0.8 \mathrm{~cm}$ diameter, $1.2-1.5 \mathrm{~cm}$ height, and density of $1.45 \pm 0.02 \mathrm{~g} / \mathrm{cm}^{3}$ and placed into a glass ampoule. To initiate polymerization, the bottom part of the ampoule with the sample was immersed at a depth of $0.2 \mathrm{~cm}$ 
TABLE 3: Specific surface areas and pore sizes for polymer hybrid nanocomposites based on PdAAm.

\begin{tabular}{lccc}
\hline Sample & $S_{\text {sp }}, \mathrm{m}^{2} / \mathrm{g}$ & Pore volume, $\mathrm{cm}^{3} / \mathrm{g}$ & Average pore radius, $\AA$ \\
\hline poly-PdAAm & 18.2 & 0.10 & 113.2 \\
$\mathrm{SiO}$ & 238.7 & 0.41 & 34.3 \\
poly-PdAAm $/ \mathrm{SiO}_{2}$ & 146.8 & 0.28 & 37.8 \\
$\mathrm{Al}_{2} \mathrm{O}_{3}$ & 123.6 & - & - \\
poly-PdAAm $/ \mathrm{Al}_{2} \mathrm{O}_{3}$ & 60.2 & 0.17 & 55.0 \\
\hline
\end{tabular}

TABLE 4: Initial rates of cyclohexene hydrogenation $(w 0)$ in the presence of hybrid polymer-immobilized Pd nanoparticles.

\begin{tabular}{|c|c|c|c|c|}
\hline \multirow{2}{*}{ Sample } & \multirow{2}{*}{ Preparation conditions } & \multicolumn{3}{|c|}{$w 0,\left(\mathrm{~mol} \mathrm{H}_{2}\right)(\mathrm{mol} \mathrm{Pd})^{-1} \mathrm{~min}^{-1}$} \\
\hline & & cycle 1 & cycle 2 & cycle 3 \\
\hline \multirow{4}{*}{ Poly-PdAAm $/ \mathrm{SiO}_{2}$} & FP & 76.5 & 55.6 & - \\
\hline & $\mathrm{FP}, 100^{\circ} \mathrm{C}$ & 36.0 & 42.0 & 36.0 \\
\hline & $\mathrm{FP}, 120^{\circ} \mathrm{C}$ & 44.5 & 35.1 & 37.5 \\
\hline & $\mathrm{FP}, 150^{\circ} \mathrm{C}$ & 3.5 & 11.6 & 17.4 \\
\hline \multirow{3}{*}{ Poly-PdAAm $/ \mathrm{Al}_{2} \mathrm{O}_{3}$} & $\mathrm{FP}$ & 111.2 & 82.8 & 75.7 \\
\hline & $\mathrm{FP}, 100^{\circ} \mathrm{C}$ & 37.8 & 33.1 & - \\
\hline & $\mathrm{FP}, 140^{\circ} \mathrm{C}$ & 8.2 & 13.3 & 14.27 \\
\hline Poly-PdAAm/C & $\mathrm{FP}$ & 37.8 & - & - \\
\hline $\mathrm{Pd} / \mathrm{C}$ & & 38.7 & 38.7 & - \\
\hline
\end{tabular}

in a bath with a heat carrier (Wood's alloy) at $80-100^{\circ} \mathrm{C}$ for 10-15 seconds (Figure 1).

The rate of reaction was evaluated from the migration of the front of a colored zone. Powdered polymer and hybrid nanocomposite were washed with methanol and ether, and dried in vacuum at room temperature to constant weight.

2.7. Hydrogenation Reactions. Hydrogenation reaction was carried out in a non-flow glass reactor under a constant atmospheric hydrogen pressure with vigorous stirring (300-400 rocking $\mathrm{min}^{-1}$ ). Hydrogen was fed into the reactor from a calibrated receiver with a water lock. The reaction rate was calculated graphically from the initial part of kinetic curves of hydrogen consumption over time. Discrepancies in parallel experiments did not exceed $5 \%$.

2.7.1. Cyclohexene Hydrogenation. The reaction was carried out at $20^{\circ} \mathrm{C}$ in isopropyl alcohol with substrate concentration of $(4.72-14.5) \times 10^{-3} \mathrm{~mol} / \mathrm{L}$. Catalyst amount was $0.06-0.12 \mathrm{~g}$. Before introducing cyclohexene, the catalyst was treated with hydrogen for $15 \mathrm{~min}$ immediately in the reactor with stirring.

2.7.2. Hydrogenation of Allylic and Acetylenic Alcohols. The reactions were carried out at $40^{\circ} \mathrm{C}$ in ethanol $(20 \mathrm{~mL})$ with substrate concentration of $2.2 \times 10^{-3} \mathrm{~mol} / \mathrm{L}$. Catalyst amount was $0.03 \mathrm{~g}$. Catalyst was pretreated by hydrogen for 30 minutes before injection of the substrate into reactor. Catalyst selectivity was evaluated as the mass fraction of the desired product in the total content of the reaction products.

2.7.3. Hydrogenation of $D i$ - and Trinitrotoluene. The reaction was carried out in methanol with concentration of substrate of $(4.72-14.5) \times 10^{-3} \mathrm{~mol} / \mathrm{L}$ at $36^{\circ} \mathrm{C}$. Catalyst was pretreated by hydrogen for 15 minutes before injection of the substrate into reactor.

2.8. Characterization. The specific surface area $\left(S_{\text {spec }}\right)$ and pore size of inorganic supports and polymer hybrid nanocomposites were determined by static volumetric method for $\mathrm{N}_{2}$ adsorption at $77 \mathrm{~K}$ (AUTOSORB-1, Quantachrome, USA).

Analysis of the products of allyl alcohol hydrogenation and isomerization was carried out on "Crystal-2000M" chromatograph (Russia) with a flame ionization detector under isothermal conditions. The universal capillary column for organic compounds of $50 \mathrm{~m}$ length and $0.20 \mathrm{~mm}$ inner diameter was used. Helium was carrier gas.

Elemental analysis was carried out by organic microanalysis and flameless atomic absorption method using spectrometer AAS3, Germany.

XPS analysis of the powders was studied by X-ray diffraction "DRON UM-2" and "Philips PW 1050" using $\mathrm{Cu}-\mathrm{K} \alpha$ radiation $(\lambda=1,54184 \AA)$.

IR absorption spectra were recorded on a Specord 75 IR using the $\mathrm{KBr}$ disc method.

Electron microscopic studies were performed using JEM3010 transmission electron microscope with an accelerating voltage of $100 \mathrm{kV}$. The samples were prepared by dispersing the diluted catalyst suspension in heptane onto copper grids.

XPS spectra were recorded on an ES-2401 spectrometer with a magnesium anode. X-ray tube power was 200 watts; a vacuum in the analyzer chamber was $10^{-6} \mathrm{~Pa}$. The analyzer energy was $50 \mathrm{eV}$. The $\mathrm{Au}_{4 / 2}$ line $(84 \mathrm{eV})$ was used to calibrate the spectrometer. The binding energy of $\mathrm{C} 1 \mathrm{~s}$ line of 
TABLE 5: Initial rates and selectivities of the hydrogenation of allyl alcohol and 3,7,11,15-tetramethylhexadec-1-yn-3-ol on Pd hybrid polymerimmobilized catalysts.

\begin{tabular}{lcccc}
\hline Catalyst & \multicolumn{2}{c}{ Allyl alcohol } & \multicolumn{2}{c}{ C20 acetylene alcohol } \\
& $w \times 10^{5}, \mathrm{~mol} \mathrm{~L}^{-1} \mathrm{~s}^{-1}$ & selectivity $(\%)$ & $w \times 10^{5}, \mathrm{~mol} \mathrm{~L}^{-1} \mathrm{~s}^{-1}$ (after 10 min) & 1.4 \\
Poly-PdAAm $/ \mathrm{Al}_{2} \mathrm{O}_{3}$ & 4.98 & 97.2 & 2.8 & 70 \\
Poly-PdAAm $/ \mathrm{SiO}_{2}$ & 56.7 & 95.6 & 2.8 & 49.9 \\
\hline
\end{tabular}

Note: reaction conditions: alcohol concentration: $0.225 \mathrm{~mol} / \mathrm{L}$; catalyst sample weight: $0.03 \mathrm{~g}\left(1.41 \times 10^{-5} \mathrm{~g}\right.$-at. of $\left.\mathrm{Pd} / \mathrm{g}\right)$; temperature: $40^{\circ} \mathrm{C}$; pressure: $0.1 \mathrm{MPa}$; solvent: $20 \mathrm{~mL}$ of ethanol.

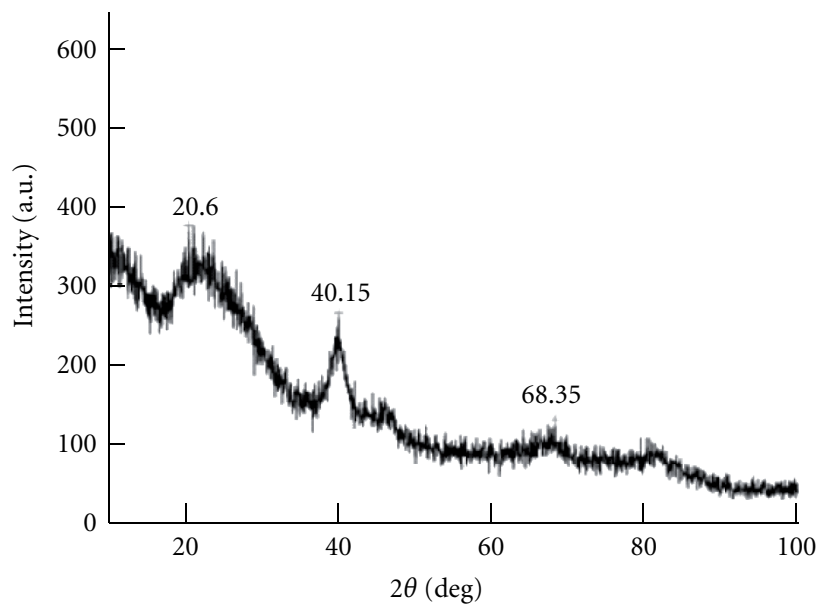

(a)

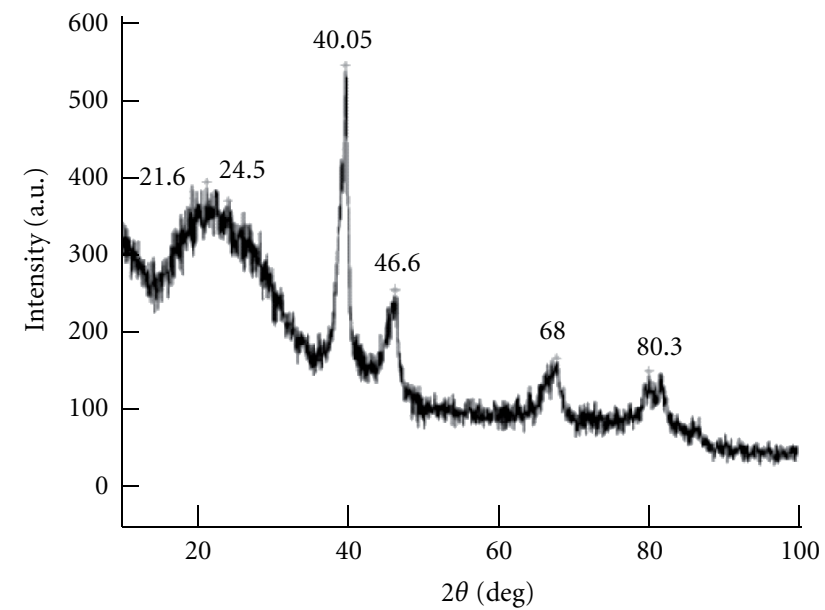

(b)

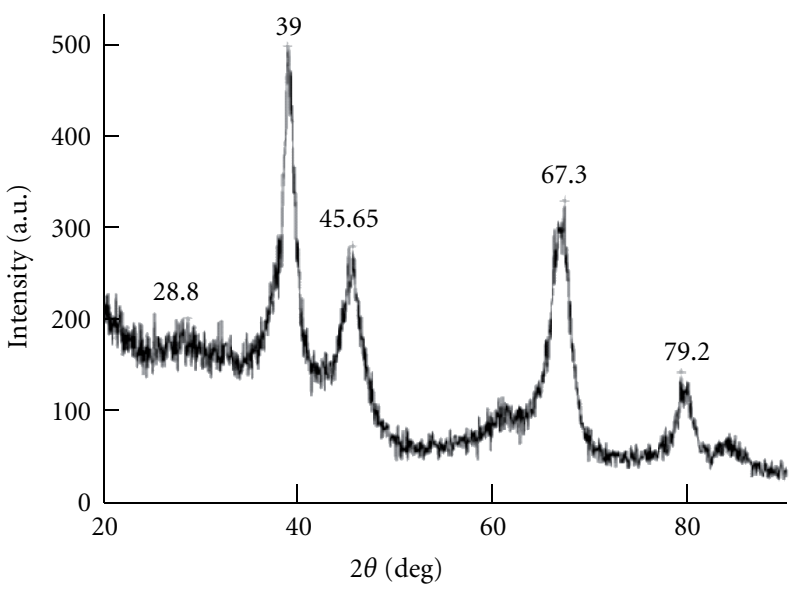

(c)

FIgURE 4: Diffraction patterns of $\mathrm{PdAAm} / \mathrm{SiO}_{2}$ samples prepared at (a) 115 and (b) $130^{\circ} \mathrm{C}$ and (c) a $\mathrm{PdAAm} / \mathrm{Al}_{2} \mathrm{O}_{3}$ sample.

electrons in alkyl group was taken as $285.0 \mathrm{eV}$. The accuracy of identification of the line positions in the scale of binding energies was 0.1-0.2 eV. Standard samples in the XPS analysis were $\mathrm{PdCl}_{2} \cdot 4 \mathrm{H}_{2} \mathrm{O}\left(E_{\text {bond }}\left(\mathrm{Pd}_{3} \mathrm{~d}_{5 / 2}\right)=337.5 \mathrm{eV}\right)$ and palladium black $\left(E_{\text {bond }}\left(\mathrm{Pd}_{3} \mathrm{~d}_{5 / 2}\right)=335.5 \mathrm{eV}\right)$.

Intermediates, products of the hydrogenation reaction, and catalysts were identified in nondestructive testing by NMR ${ }^{1} \mathrm{H}$ in acetone- $\mathrm{d}_{6}$ using NMR spectrometer Bruker AC200P (1H $200 \mathrm{MRC}$ ), as well as X-ray diffraction of powders and by XPS method.

\section{Results and Discussion}

3.1. Synthesis of $\mathrm{Pd}\left(\mathrm{CH}_{2}=\mathrm{CHCONH}_{2}\right)\left(\mathrm{NO}_{3}\right)_{2}(\mathrm{PdAAm})$. Acrylamide complex of $\mathrm{Pd}(\mathrm{II})$ nitrate was synthesized by substitution of crystallization water in crystalline hydrate of metal nitrate by acrylamide molecules (AAm). Elemental analysis and some spectral characteristics of the complex are given in Table 1.

The infrared spectroscopy data indicated coordination of metal atom with the oxygen atoms of carbonyl group of 


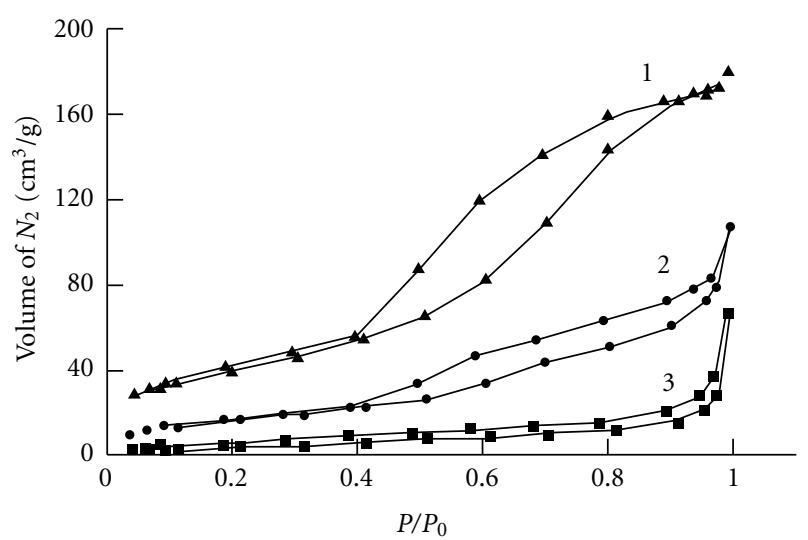

(a)

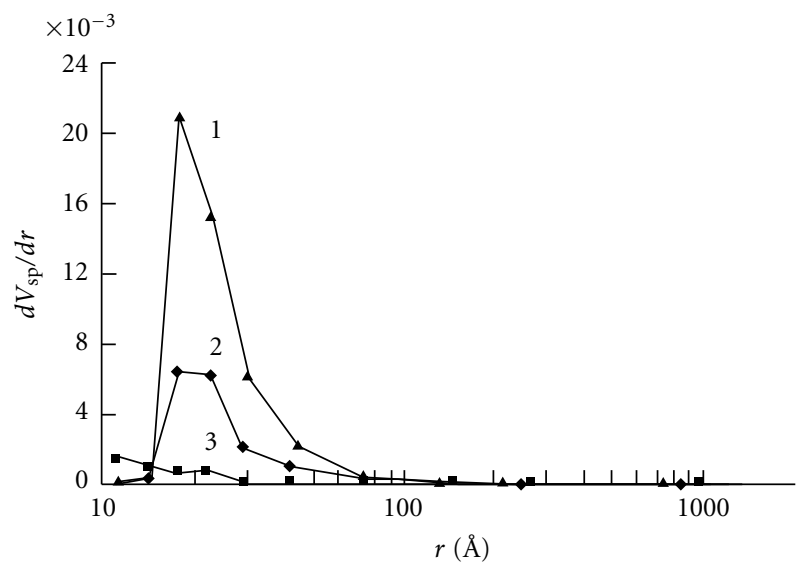

(b)

FIGURE 5: (a) Nitrogen adsorption-desorption isotherms and (b) differential pore radius $(r)$ distribution curves in polymer hybrid nanocomposites: (1) poly-PdAAm/SiO ${ }_{2}$, (2) poly-PdAAm $/ \mathrm{Al}_{2} \mathrm{O}_{3}$, and (3) poly-PdAAm.

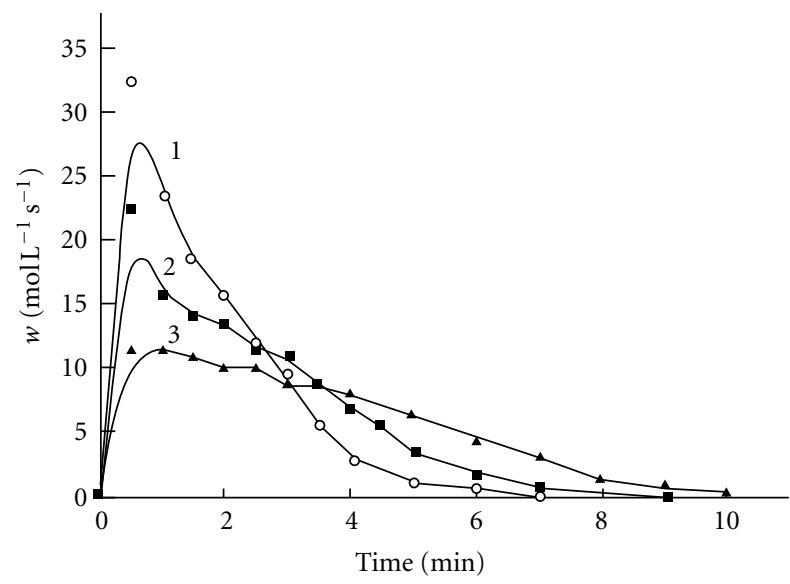

FIGURE 6: Hydrogen uptake kinetics in cyclohexene hydrogenation in the presence of (1) poly- $\mathrm{PdAAm} / \mathrm{Al}_{2} \mathrm{O}_{3}$, (2) poly- $\mathrm{PdAAm} / \mathrm{SiO}_{2}$, and (3) $\mathrm{Pd} / \mathrm{C}$. Catalyst sample weight: $0.05-0.10$ g; temperature: $20^{\circ} \mathrm{C} ; \mathrm{H}_{2}$ pressure: $0.1 \mathrm{MPa}$; solvent: isopropanol; initial cyclohexene amount: $6.9 \mathrm{mmol}$.

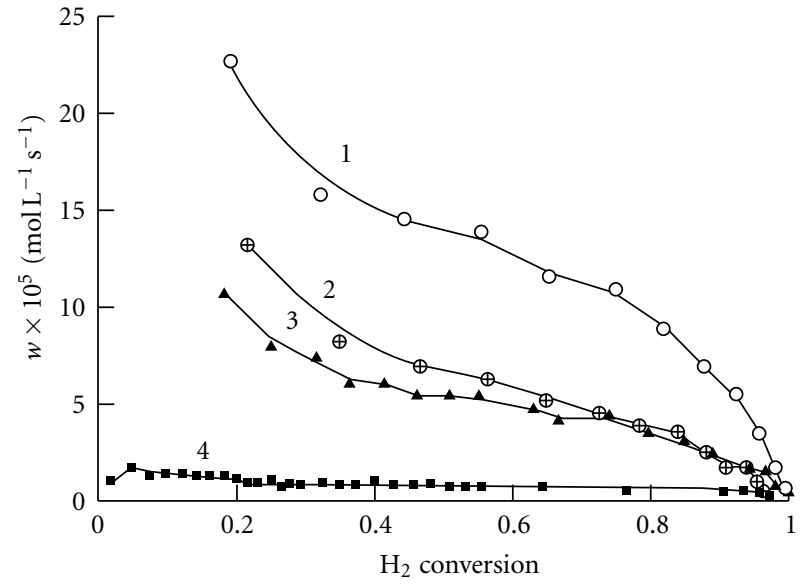

FIgURE 7: Dependence of the rate of cyclohexene hydrogenation on the $\mathrm{H}_{2}$ conversion in the presence of poly- $\mathrm{PdAAm} / \mathrm{SiO}_{2}$ samples prepared under various conditions: (1) frontal polymerization in a self-generated atmosphere, (2) frontal polymerization in a reductive atmosphere at $118-120^{\circ} \mathrm{C},(3)$ the same at $104-106^{\circ} \mathrm{C}$, and (4) the same at $150^{\circ} \mathrm{C}$. Catalyst sample weight: 0.10 g; temperature: $20^{\circ} \mathrm{C} ; \mathrm{H}_{2}$ pressure: $0.1 \mathrm{MPa}$; solvent: isopropanol; initial cyclohexene amount: $6.9 \mathrm{mmol}$.

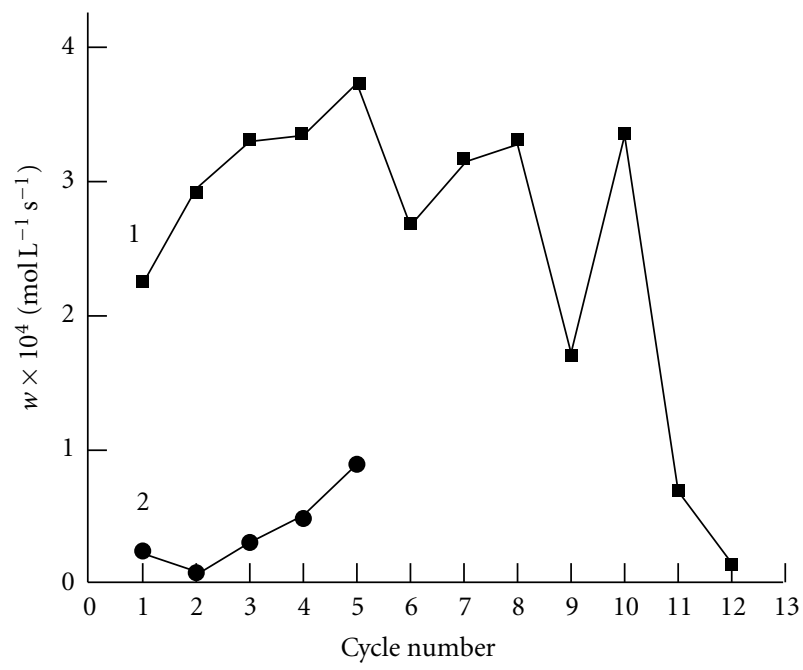

FIgURE 8: Consecutive hydrogenation of allyl alcohol portions in the presence of (1) poly-PdAAm $/ \mathrm{SiO}_{2}$ and (2) poly-PdAAm/ $/ \mathrm{Al}_{2} \mathrm{O}_{3}$. Initial substrate amount is $2.58 \mathrm{mmol}$; catalyst sample weight is $0.03 \mathrm{~g}$; solvent: $20 \mathrm{~mL}$ of ethanol; temperature: $40^{\circ} \mathrm{C}$.

AAm-ligand. Bands $v \mathrm{CO}\left(1665 \mathrm{~cm}^{-1}\right)$ are shifted into longwave region as it was shown previously for similar complexes of transition metals [20]. The valence vibration bands of anion-nitrate at $1384 \mathrm{~cm}^{-1}\left(\nu \mathrm{NO}_{3}\right)$ were also observed in the spectra of the complexes. In XPS spectra the shifts of lines $8 \mathrm{C} 1 \mathrm{~s}$ (bond energy $\left.E_{\text {bond }}=288.3 \mathrm{eV}\right)$, N1s $\left(E_{\text {bond }}=\right.$ $399.8 \mathrm{eV})$ and $\mathrm{O} 1 \mathrm{~s}\left(E_{\mathrm{bond}}=531.6 \mathrm{eV}\right)$ by $0.5,0.7$, and $0.5 \mathrm{eV}$ to high-energy region correspondingly were observed. The appearance of a low-intensity line with $E_{\text {bond }}=337.2 \mathrm{eV}$ in $\operatorname{Pd} 3 \mathrm{~d}_{5 / 2}$ spectrum and the increase in the intensity of the line with $E_{\text {bond }}=285.7 \mathrm{eV}$ could be explained by additional 


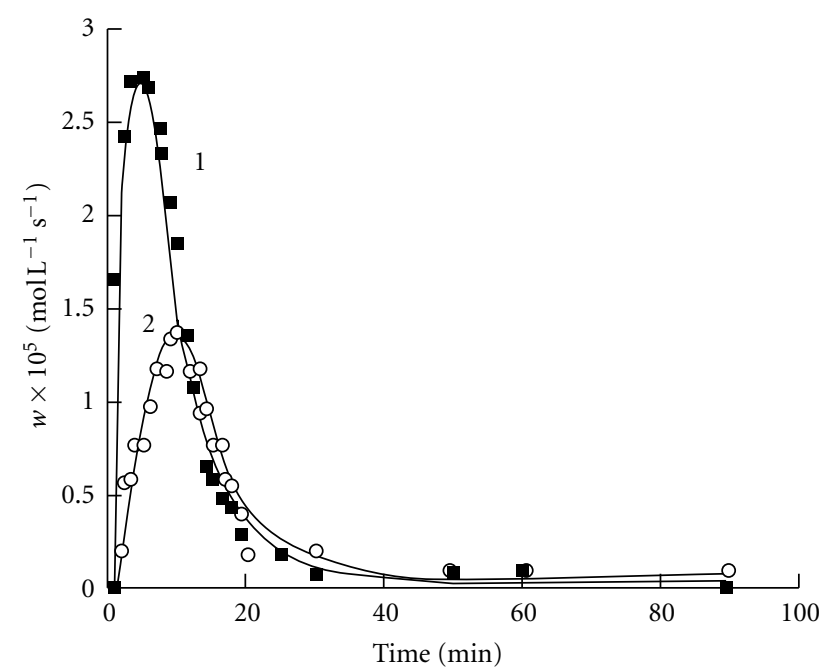

FIgURE 9: Time variation of the rate of 3,7,11,15-tetramethylhexadec-1-yn-3-ol hydrogenation on immobilized (1) poly$\mathrm{PdAAm} / \mathrm{SiO}_{2}$ and (2) poly-PdAAm $/ \mathrm{Al}_{2} \mathrm{O}_{3}$ catalysts. Catalyst sample weight is $0.03 \mathrm{~g}$; temperature is $40^{\circ} \mathrm{C} ; \mathrm{H}_{2}$ pressure is $0.1 \mathrm{MPa}$; solvent is $20 \mathrm{~mL}$ of ethanol.

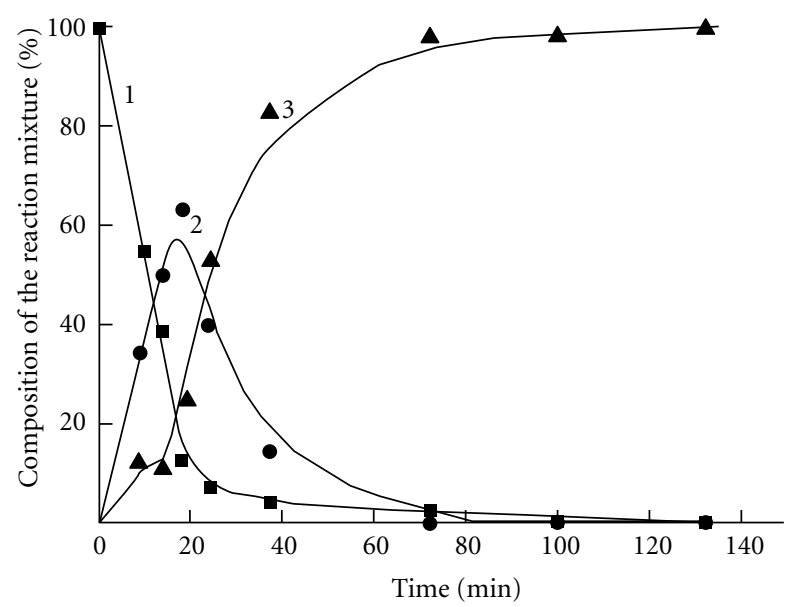

Figure 10: Changes in the composition of the reaction mixture during 3,7,11,15-tetramethylhexadec-1-yn-3-ol hydrogenation in the presence of poly-PdAAm/SiO ${ }_{2}$ : (1) C20 acetylene alcohol, (2) the resulting ethylene alcohol, and (3) the resulting saturated alcohol. Catalyst sample weight is $0.03 \mathrm{~g}$; temperature is $40^{\circ} \mathrm{C} ; \mathrm{H}_{2}$ pressure is $0.1 \mathrm{MPa}$; initial C20 content is $0.225 \mathrm{~mol} / \mathrm{L}$.

$\pi$-coordination of metal atom with the double bond of the ligand. Such examples for Pd-alkene complexes are known [21]. For the surface layer the ratio of $\mathrm{Pd} / \mathrm{N}$ atoms is equal to 0.11 and $\mathrm{O} / \mathrm{N}=1.4$ (Table 1 ).

The line in the N1s spectrum with $E_{\text {bond }}=407.2 \mathrm{eV}$ is $10 \%$ of the integral spectral intensity, correlating with the line intensity in the $\operatorname{Pd} 3 \mathrm{~d}_{5 / 2}$ spectrum with $E_{\text {bond }}=$ $338.8 \mathrm{eV}$ and indicating that the $\mathrm{Pd}$ atoms are shielded by the AAm groups. The results of elemental analysis and study by physical and chemical methods confirm the formation of a palladium complex of the following composition: $\mathrm{Pd}\left(\mathrm{CH}_{2}=\mathrm{CHCONH}_{2}\right)_{2}\left(\mathrm{NO}_{3}\right)_{2}(\mathrm{PdAAm})$.

3.2. PdAAm Frontal Polymerization with and without Inorganic Support. As shown earlier [20, 22], the acrylamide complexes of metal nitrates in the condensed state can efficiently be polymerized in the frontal mode, that is, under the conditions when the monomer is converted to the polymer in the localized reaction zone and is propagated by layers over the whole volume. The reaction occurs under mildest conditions known for processes of this type, at atmospheric pressure and thermal initiation without chemical initiators and activators. In the mode of stationary propagation of the heat wave, polymerization occurs in a narrow temperature interval. The heat evolved in the reaction zone is transmitted to the heating zone, where the substance is heated due to heat conductivity and the temperature increases from the initial value to the temperature at which the reaction starts, that is, the polymerization front is propagated. The heat wave is initiated upon the short-term $(\sim 15 \mathrm{~s})$ introduction of thermal perturbation into the terminal part of the PdAAm monomer sample molded as a cylinder of the system with the inorganic support. The appearance and propagation of the melt zone (phase transition of the first order) (Figure 1) and the color change (the reaction rate was monitored by the migration of the color boundary) from light brown to dark brown and black were visually observed. Kinetic studies showed the high rate of frontal polymerization of $\mathrm{Pd}$ (II) acrylamide complex $(w=0.038 \mathrm{~cm} / \mathrm{s})$ for which the "ignition" temperature $\left(80-100^{\circ} \mathrm{C}\right)$ was much lower than for AAM complexes with $\mathrm{Co}(\mathrm{II}), \mathrm{Ni}(\mathrm{II})$ nitrates and other metal ions $\left(170-180^{\circ} \mathrm{C}\right)$ [20].

At higher ignition temperatures $\left(150-170^{\circ} \mathrm{C}\right)$, we observed the release of the reaction mass from a glass tube and the combustion mode (!), that probably were caused by the formation of fine particles of pyrophoric palladium. According to XPS data, the basic line in Pd3d5/2-spectrum of polymerization product (Figure 2) is characterized by $E_{\text {bond }}=336.5 \mathrm{eV}$, which is higher than $E_{\text {bond }}$ in $\operatorname{Pd} 0$ $(336.0 \mathrm{eV})$ because of formation of fine particles of $\mathrm{Pd}^{0}$ and $\operatorname{Pd}^{\delta+}[9,23]$.

Increase in $E_{\text {bond }}$ of basic line in the N1s spectrum from 399.8 to $401.7 \mathrm{eV}$ is probably caused by the reaction of cyclization of polymer chains and formation of imide groups [24] (see Scheme 1).

Previously developed approach to obtaining nanocomposite materials by the frontal polymerization [25] is of interest for the design of polymer-immobilized catalysts of mixed (hybrid) type: metal nanoparticles-polymer-inorganic support. Indeed, synthesis of $\mathrm{Pd}(\mathrm{II})$ acrylamide complex on the surface of the mineral support and its subsequent polymerization lead to formation of polymer-inorganic composite (e.g., poly-PdAAm/SiO ${ }_{2}$ ) (see Scheme 2).

According to electron microscopy data, the resulting composite includes $\mathrm{Pd}$ nanoparticles with a diameter of $10-20 \mathrm{~nm}$, stabilized with a polymer matrix (Figure 3 ). 


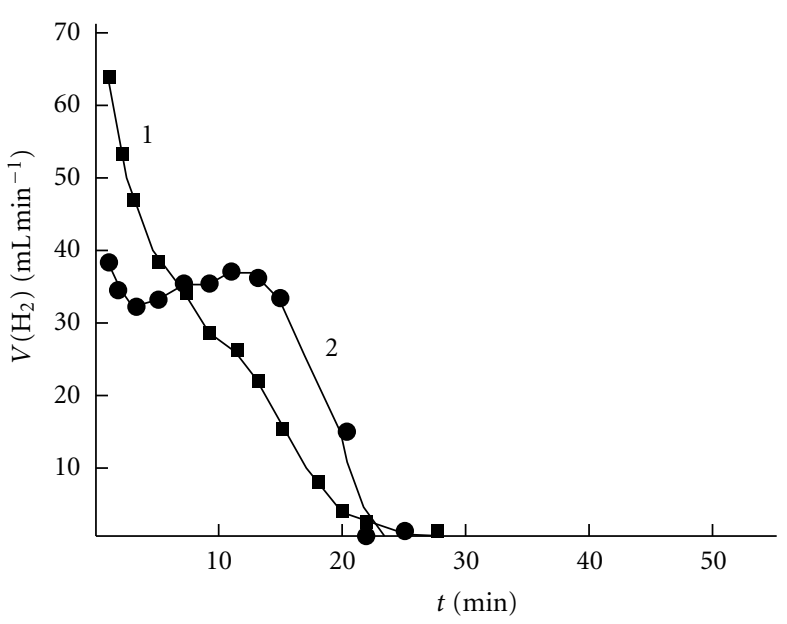

(a)

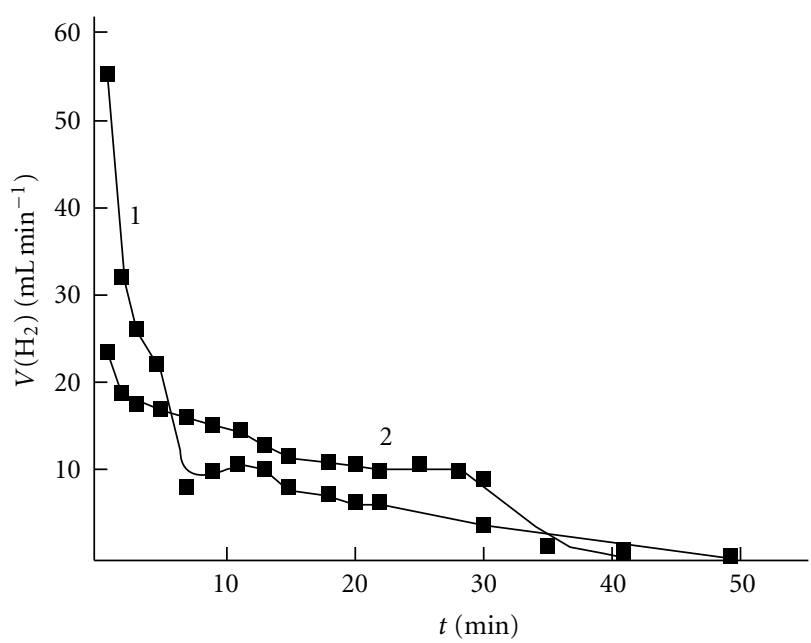

(b)

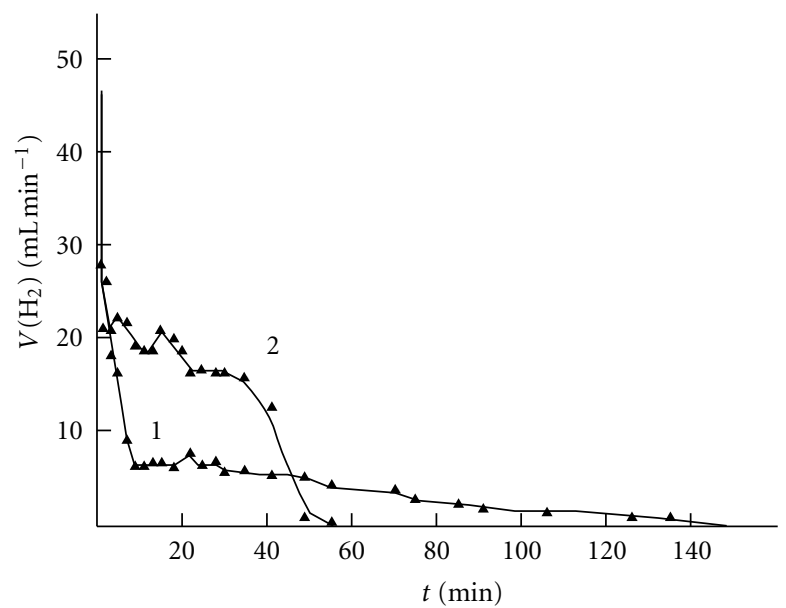

(c)

FIGURE 11: Hydrogen absorption rate as a function of the duration of the hydrogenation of nitrotoluene (a), 2,4-dinitrotoluene (b), and 2,4,6trinitrotoluene (c) in the presence of poly- $\mathrm{PdAAm} / \mathrm{SiO}_{2}$ obtained by frontal polymerization (1) and $\mathrm{Pd} / \mathrm{C}(2)$. Conditions: catalyst content is $9.76 \times 10^{-5}(\mathrm{a}), 8.58 \times 10^{-5}(\mathrm{~b})$, and $1.1 \times 10^{-4} \mathrm{~g}$-at. of $\mathrm{Pd} \mathrm{g}^{-1}$ (c); substrate content is 7.29 (a), $2.36(\mathrm{~b})$, and $2.46 \mathrm{mmol}(\mathrm{c})$; methanol (50 mL); temperature $36^{\circ} \mathrm{C}, P\left(\mathrm{H}_{2}\right)=1$ atm.

As expected, the stabilizing effect of the fillers- $\mathrm{SiO}_{2}$ $\left(\mathrm{Al}_{2} \mathrm{O}_{3}, \mathrm{C}\right)$ on autowave mode of polymerization. $(w=$ $0.024 \mathrm{~cm} / \mathrm{s}$ ) shows that the polymerization front becomes space-time stable: thermophysical properties of the system are such that frontal mode is carried out with a high (75 wt.\%) degree of filling. Wide diffraction peaks at $2 \Theta=36-85$ degrees corresponding to crystal $\mathrm{Pd}^{0}$ were registered on $\mathrm{X}$ ray diagram for synthesized composites (Figure 4).

The diffuse diffraction maxima and line broadening indicate that the sample contains small particles (Table 2 ). The prepared nanocomposites are characterized by a microporous structure with pore sizes from several $\mathrm{nm}$ to $20 \mathrm{~nm}$ and uniform size distribution (Figure 5). It should be noted that the specific surface of the mixed-type supports decreases after PdAAm frontal polymerization on their surface, although its value is higher than $S_{\text {sp }}$ of PdAAm polymerization product prepared without inorganic support (Table 3). Thus, the synthesized hybrid nanocomposites have sufficiently developed surface and a porous structure that provides access of reactants to active sites of the catalyst and their high activity in the studied catalytic reactions.

3.3. Catalytic Properties of $\mathrm{PdAAm} / \mathrm{SiO}_{2}\left(\mathrm{Al}_{2} \mathrm{O}_{3}, \mathrm{C}\right)$ in the Reaction of Cyclohexene Hydrogenation. The analyzed systems showed sufficiently high activity in the model reaction of cyclohexene hydrogenation. Thus, under comparable conditions, the initial reaction rate in the presence of poly$\mathrm{PdAAm} / \mathrm{Al}_{2} \mathrm{O}_{3}$ catalyst nearly 2-times higher than that for the standard Pd/C (Table 4, Figure 6).

It is important that the studied nanocomposites keep high catalytic activity in the recycle, and the immobilized form is easily separated from the reaction medium and can be reused. Even more importantly, it provides an opportunity to explore catalytic intermediates by various physical and chemical methods of nondestructive testing. In some cases, there is increased activity with repeated use, so-called "developing" 


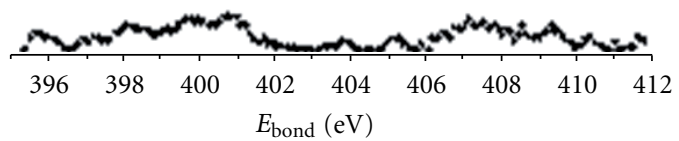

N1S

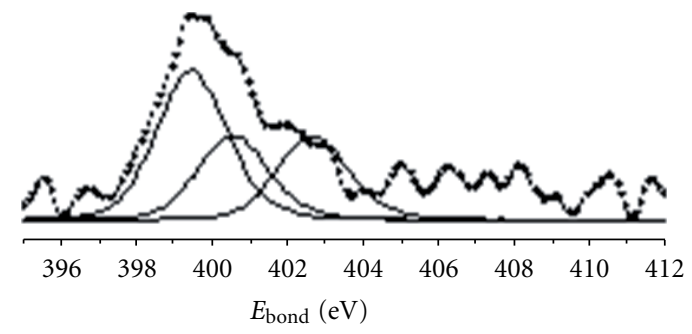

$\operatorname{Pd} 3 \mathrm{~d}$

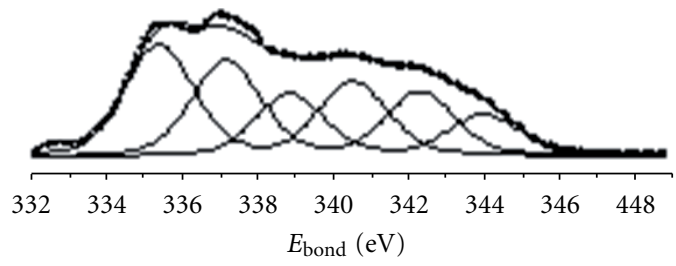

(a)

$\operatorname{Pd} 3 \mathrm{~d}$

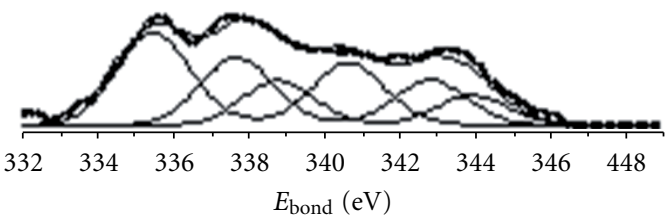

(b)

FIGURE 12: X-ray photoelectron spectra of poly-PdAAm/SiO 2 : after the hydrogenation of $p$-nitrotoluene (a) and 2,4-dinitrotoluene (b).

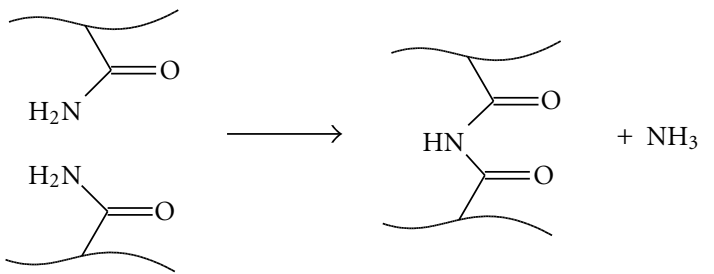

SCHEME 1

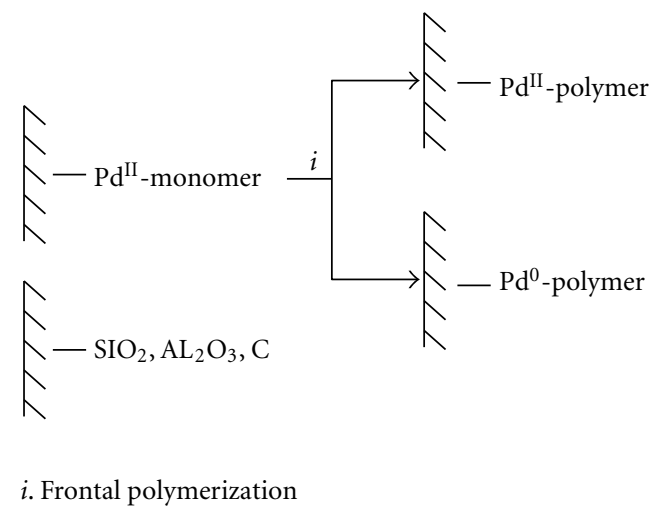

SCHEME 2

of the catalysts, which is typical for many of immobilized systems. The phenomenon recently was demonstrated for polymer rhodium clusters [26].

Conditions for formation of Pd nanoparticles also effect the catalytic properties of the composites, for example, different modes of frontal polymerization in an inert environment or afterheat treatment at $100-150^{\circ} \mathrm{C}$ in a reduction atmosphere $\left(\mathrm{H}_{2}\right)$ (Figure 7$)$. Thus, the rate of hydrogenation on the nanocomposites obtained by this method decreases with increasing temperature of their reduction.

Similar effect is observed for catalysts with both $\mathrm{SiO}_{2}$ and $\mathrm{Al}_{2} \mathrm{O}_{3}$ (Table 4). Probable reason for the decreasing reaction rate is agglomeration of $\mathrm{Pd}$ particles at higher temperatures of treatment in the process of nanocomposite preparation.

After hydrogenation the basic part of $\mathrm{Pd}(90 \%)$ in polyPdAAm is in zero valence state (the line of $\mathrm{Pd} \mathrm{d}_{5 / 2}$ spectrum with $E_{\text {bond }}=335.9 \mathrm{eV}$ ) (see Figure 2) and its shielding by the polymer matrix is decreased, as it is evidenced by increasing Pd content in the surface layer (from 1.5 at.\% in the initial polymer complex to 4.3 at.\%). Polymer matrix is also changed, which is confirmed by the broadening of N1s spectrum.

Thus, the hybrid polymer-immobilized Pd nanoparticles show high stable activity in the hydrogenation of cyclohexene. The catalysts preserve their activity in repeated cycles. The catalytic properties depend on the conditions of nanocomposite synthesis, which is probably associated with the formation of Pd nanoparticles of different sizes.

3.4. Catalytic Properties of Poly-PdAAm/SiO $2\left(\mathrm{Al}_{2} \mathrm{O}_{3}\right) \mathrm{Nano}-$ composites in the Hydrogenation of Allyl Alcohol. It is known that hydrogenation of allyl alcohol is often accompanied by undesirable side reaction of substrate isomerization, which sometimes may even prevail over the main process. Therefore minimization of isomerization is essential for increasing the yield of the target hydrogenation products. For example, catalysts based on Pd nanoparticles encapsulated in polyelectrolyte multilayers [27] or dendrimers [28] were used for this purpose. 
The synthesized Poly-PdAAm/ $\mathrm{SiO}_{2}\left(\mathrm{Al}_{2} \mathrm{O}_{3}\right)$ catalysts show different activity and high selectivity in the hydrogenation of allyl alcohol (Table 5). The main product of allyl alcohol hydrogenation is propanol1, propionaldehyde-a product of the allyl alcohol isomerization is identified in small amount (up to $2 \%$ on poly-PdAAm $/ \mathrm{Al}_{2} \mathrm{O}_{3}, 5 \%$-in the presence of poly$\mathrm{PdAAm} / \mathrm{SiO}_{2}$ ). No other products were detected. Higher reaction rate over $\mathrm{PdAAm} / \mathrm{SiO}_{2}$ catalyst is apparently explained by more developed surface area of the catalyst and the specific adsorption of the substrate molecule on the surface of catalysts (see Table 3).

The stability of the catalysts was evaluated in hydrogenation of successive portions of allyl alcohol on the same catalyst loading (Figure 8). Poly-PdAAm/ $\mathrm{SiO}_{2}$ catalyst shows high activity in repeated cycles; the rate has decreased only after 11 reaction runs. Interrupting the process for several hours (portions 7 and 10) apparently leads to the increasing of the reaction rate due to equalization of the concentrations of all process components (solvent, products, and substrate) near the active centers.

3.5. Catalytic Properties of $\mathrm{PdAAm} / \mathrm{SiO}_{2}\left(\mathrm{Al}_{2} \mathrm{O}_{3}\right)$ Nanocomposites in the Hydrogenation of 3,7,11,15-Tetramethylhexadecine-1-ol-3 (C20). A steric effect on the selectivity of the catalytic reaction is conveniently demonstrated by hydrogenation of hindered long chain acetylene alcohol. While the overall trend in activity and selectivity of the studied catalysts are similar, the rate of hydrogenation to compare with one for allyl alcohol is significantly decreased (Figure 9, Table 5), which may be due to diffusion restrictions of access of the reagent to the active centers of the nanoparticles.

According to chromatographic analysis (Figure 10) the triple bond of $\mathrm{C}_{20}$ acetylene alcohol is reduced with high rate to a double one. The reaction rate reaches a maximum at the 10th minute (see Figure 9) and then drastically decreases to $(0.05-0.1) \cdot 10^{-5} \mathrm{~mol} / \mathrm{L}$. During this time, $100 \%$ conversion of acetylene alcohol to reaction products is achieved on poly$\mathrm{PdAAm} / \mathrm{SiO}_{2}$ catalyst. However, the process is not selective. Hydrogenation of the triple bond of acetylene alcohol occurs simultaneously with the reduction of forming double bond: both saturated 3,7,11,15-tetramethylhexadecane-1-ol-3 and olefinic alcohol are detected in the reaction products.

Somewhat different results were obtained for the hydrogenation of $\mathrm{C} 20$ acetylenic alcohol in the presence of the poly-PdAAm $/ \mathrm{Al}_{2} \mathrm{O}_{3}$. Initially, acetylene alcohol is mainly converted to olefinic one. And only after 20 minutes when the content of the initial substrate in the reaction mixture is about 10\%, 3,7,11,15-tetramethylhexadecene-1-ol-3 formed is hydrogenated to aliphatic alcohol. Selectivity for olefin alcohol is 70\% (Table 5). Comparison of the data of chromatographic analysis and the reaction rates makes it possible to conclude that acetylene alcohol with high rate is converted to alkenol, but the formation of a saturated alcohol is 7-10times slower $\left(w=0.1 \cdot 10^{-5} \mathrm{~mol} / \mathrm{L}\right)$. Currently, the mechanism of selective action of hybrid polymer-immobilized catalysts obtained is not completely clear and requires further study, as well as optimization of the catalytic process.

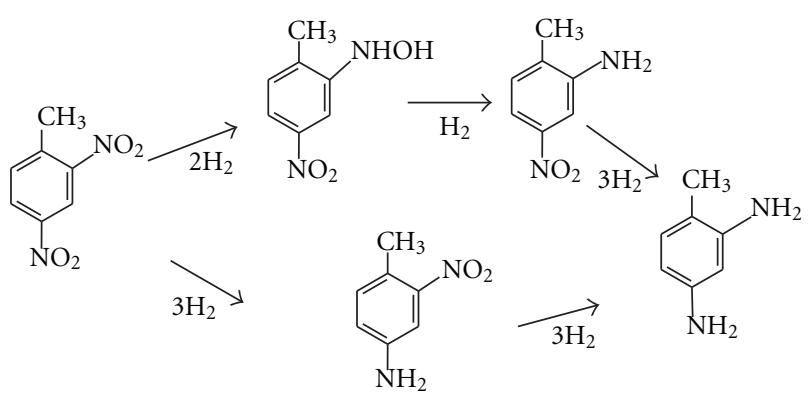

SCHEMe 3

3.6. Catalytic Properties of $\mathrm{PdAAm} / \mathrm{SiO}_{2}$ in Hydrogenation of Nitro Derivatives of Toluene. Kinetics of hydrogenation of 2,4-dinitro-(DNT) and 2,4,6-trinitrotoluene (TNT) on poly$\mathrm{PdAAm} / \mathrm{SiO} 2$ (curves 1 ) and usual $\mathrm{Pd} / \mathrm{C}$ catalyst (curves 2 ) are compared in Figure 11. The reaction rates of 2,4-DNT and 2,4,6-TNT hydrogenation on poly- $\mathrm{PdAAm} / \mathrm{SiO}_{2}$ decrease by nearly ten times at conversion of $1 / 2$ and $1 / 3$, respectively. In case of $\mathrm{Pd} / \mathrm{C}$ the rate of hydrogenation remains practically unchanged till complete conversion of 2,4-DNT. It is known that nitro groups of polynitrocompounds can be hydrogenated stepwise to the corresponding polyamines [29]. The kinetic curves indicate that the rate of formation of monoamine derivatives in the presence of the polymerimmobilized catalyst is significantly higher than for Pd/C. In addition, hydrogenation of the second and third (for TNT) nitro groups is carried out at lower rates than the first one.

To identify the main routes of nitro groups' reduction in the studied processes, we have analyzed the composition of the reaction mixtures by ${ }^{1} \mathrm{H}$ NMR. Indeed, the ${ }^{1} \mathrm{H}$ NMR spectrum of reaction mixture recorded after $\sim 1 / 2$ conversion of 2,4-dinitrotoluene indicates the presence of 4-amino2-nitrotoluene (4A2NT) (4A2NT) $\left({ }^{1} \mathrm{H}\right.$ NMR, $\delta: 2.70(\mathrm{~s}$, $3 \mathrm{H}, \mathrm{CH}_{3}$ ) (s-singlet, d-doublet, dd-doublet of doublets, bdbroadened); $6.89(\mathrm{dd}, 1 \mathrm{H}) ; 7.11(\mathrm{~d}, 1 \mathrm{H}) ; 7.23(\mathrm{~d}, 1 \mathrm{H}) ; 7.54$ (d, $1 \mathrm{H}, \mathrm{H}(3), 6.67, \mathrm{~s}, \mathrm{bd}, 1 \mathrm{H}, \mathrm{NH}_{2}$ ), 2-(hydroxy)amino-4 nitrotoluene (2HA4NT) $\left({ }^{1} \mathrm{H}\right.$ NMR, $\delta: 2.22\left(\mathrm{~s}, 3 \mathrm{H}, \mathrm{CH}_{3}\right) ; 7.10$ (d, $1 \mathrm{H}, \mathrm{H}(3)$ ); 6.67 (s, bd, $1 \mathrm{H}, \mathrm{NH}_{2}$, or $\mathrm{NHOH}$ ), 2-amino-4nitrotoluene (2A4NT) $\left({ }^{1} \mathrm{H}\right.$ NMR $\delta: 2.22\left(\mathrm{~s}, 3 \mathrm{H}, \mathrm{CH}_{3}\right) ; 7.11$ (d, 1H, H(6)); 7.38 (dd, 1H, H(5), 7.54 (d, 1H, H(3)), 6.67 (s, bd, $1 \mathrm{H}, \mathrm{NH}_{2}$, or $\mathrm{NHOH}$ ). Some unidentified peaks in the spectrum probably refer to products of condensation and oxidation, which can be formed during the sampling at NMR analysis. These results confirm stepwise hydrogenation of 2,4$\mathrm{DNT}$ in the presence of poly- $\mathrm{PdAAm} / \mathrm{SiO}_{2}$. According to the composition of the reaction mixture, the scheme of major transformations in the reaction system can be represented as follows shown in see Scheme 3.

The presence of 4A2NT among intermediate compounds indicates the possibility of parallel reaction routes that is consistent with references [29-31]. As the authors of the paper [29] have rightly noted the final mechanism of main conversions of toluene nitroderivatives has not been yet elucidated. Probably, the use of the considered hybrid nanocomposite catalysts will help to solve this problem. On the one hand, the steric factors, including those caused 
by the presence of the polymer matrix, can lead to strong differentiation in coordination of substrate nitro groups. Consequently, the adsorption of the second and third nitro group will be much weaker. On the other hand, this type of contacts [2] allows to use methods of nondestructive testing for intermediate aromatic nitroamine; their different reactivity is demonstrated in many systems [30-32].

Thus, due to the immobilized form of the studied catalysts, it was possible to separate catalytic intermediate after reduction of the first nitro group of 2,4-DNT and analyze it by XPS, as well as to compare the resulting spectrum with the $\mathrm{Pd} 3 \mathrm{~d}_{5 / 2}$ spectrum of the catalyst, separated after complete hydrogenation of 2,4-dinitrotoluene (Figure 12). The analysis showed that the intermediate contains, along with $\mathrm{Pd}^{0}(335.5 \mathrm{eV})$, palladium atoms with partially positively charged $\mathrm{Pd}^{\delta+}(337.0 \mathrm{eV})$, promoting coordination of substrate molecules that affect the activity of the catalyst and, probably, a preferential hydrogenation of one nitro group. The shift to higher binding energy region $(337.7 \mathrm{eV})$ is observed for the intermediate separated after hydrogenation of the second nitrogroup. In this case, the polymer matrix is significantly changed, as evidenced by changes in the N1s spectrum.

\section{Conclusions}

Effective approach to obtain mixed-type catalysts based on polymer-immobilized Pd nanoparticles on the support surface has been developed for selective hydrogenation of unsaturated compounds. In the case of unsaturated alcohols, hydrogenation process prevails over isomerization. The studied nanocomposites showed stable catalytic activity in repeated cycles. The circumstance that they occurred in an immobilized form facilitated their separation from the reaction medium and repeated use and made it possible to study the transformations of catalytic intermediates, as well as to study changes in catalyst intermediates by methods of nondestructive testing. The highest activity in the hydrogenation of both double bonds and nitrotoluene compounds showed the catalysts with $\mathrm{Pd}^{\delta+}$ form where the palladium atoms are activated by the appearance of positive charge on them.

\section{Acknowledgment}

The authors are grateful to A. K. Zharmagambetova, A. M. Lyakhovich, N. D. Golubeva, V. Dorokhov, and S. I. Pomogailo for assistance. They thank the Russian Foundation for Basic Research (project no. 11-03-00769) and the Presidium of Russian Academy of Sciences, program no. 24 "Foundations for Basic Research in Nanotechnologies and Nanomaterials" for partial financial support of this work.

\section{References}

[1] A. D. Pomogailo and V. N. Kestelman, Metallopolymer Nanocomposites, Springer, Heidelberg, Germany, 2005.

[2] A. D. Pomogailo, "Catalysis by heterogenized metal polymers: advances and prospects," Kinetics and Catalysis, vol. 45, no. 1 , pp. 61-103, 2004.
[3] D. Wohrle and A. D. Pomogailo, Metal Complexes and Metals in Macromolecules, Wiley-VCH, Weinheim, Germany, 2003.

[4] J. M. Campelo, D. Luna, R. Luque, J. M. Marinas, and A. A. Romero, "Sustainable preparation of supported metal nanoparticles and their applications in catalysis," ChemSusChem, vol. 2, no. 1, pp. 18-45, 2009.

[5] R. F. Heck, Palladium Reagents in Organic Synthesis, Academic Press, New York, NY, USA, 1985.

[6] C. M. Andersson, K. Karabelas, A. Hallberg, and C. Andersson, "Palladium/phosphinated polystyrene as a catalyst in the heck arylation. A comparative study," Journal of Organic Chemistry, vol. 50, no. 20, pp. 3891-3895, 1985.

[7] S. Ogasawar and S. Kato, "Palladium nanoparticles captured in microporous polymers: a tailor-made catalyst for heterogeneous carbon cross-coupling reactions," Journal of the American Chemical Society, vol. 132, no. 13, pp. 4608-4613, 2010.

[8] M. Hirai, N. I. Yakaru, Y. Seta, and S. Hodosima, "Characterization of palladium nanoparticles protected with polymer as hydrogenation catalyst," Reactive and Functional Polymers, vol. 37, no. 1-3, pp. 121-131, 1998.

[9] A. A. Belyi, L. G. Chigladze, A. L. Rusanov et al., "Effect of the nature of the polymeric carrier on the catalytic activity of palladium-polyheteroarylene catalysts in hydrogenation reactions," Bulletin of the Academy of Sciences of the USSR, vol. 36, no. 10, pp. 1995-1999, 1987.

[10] S. Kidambi, J. Dai, J. Li, and M. L. Bruening, "Selective hydrogenation by $\mathrm{Pd}$ nanoparticles embedded in polyelectrolyte multilayers," Journal of the American Chemical Society, vol. 126, no. 9, pp. 2658-2659, 2004.

[11] F. D. Bellamy and K. Ou, "Selective reduction of aromatic nitro compounds with stannous chloride in non acidic and non aqueous medium," Tetrahedron Letters, vol. 25, no. 8, pp. 839-842, 1984.

[12] V. V. Rozhkov, S. A. Shevelev, I. I. Chervin, A. R. Mitchell, and R. D. Schmidt, "Direct amination of 1-substituted 3,5dinitrobenzenes by 1,1,1-trimethylhydrazinium iodide," Journal of Organic Chemistry, vol. 68, no. 6, pp. 2498-2501, 2003.

[13] K. B. van Gelder, J. K. Damhof, P. J. Kroijenga, and K. R. Westerterp, "Three-phase packed bed reactor with an evaporating solvent-I. Experimental: the hydrogenation of 2,4,6trinitrotoluene in methanol," Chemical Engineering Science, vol. 45, no. 10, pp. 3159-3170, 1990.

[14] L. G. Simonova, V. V. Barelko, A. V. Toktarev et al., "Catalysts based on fiberglass supports: III. Properties of supported metals (Pt and Pd) according to electron-microscopic and XPS data," Kinetics and Catalysis, vol. 42, no. 6, pp. 837-846, 2001.

[15] S. V. Belyaev, E. F. Vainshtein, and M. V. Kluev, "Effect of the polymeric matrix of a catalyst on its activity in hydrogenation," Kinetics and Catalysis, vol. 43, no. 2, pp. 245-248, 2002.

[16] A. Alonso, A. Shafir, J. Macanás, A. Vallribera, M. Munoz, and D. N. Muraviev, "Recyclable polymer-stabilized nanocatalysts with enhanced accessibility for reactants," Catalysis Today, vol. 193, no. 1, pp. 200-206, 2012.

[17] A. D. Pomogailo, G. I. Dzhardimalieva, A. S. Rozenberg, and D. N. Muraviev, "Kinetics and mechanism of in situ simultaneous formation of metal nanoparticles in stabilizing polymer matrix," Journal of Nanoparticle Research, vol. 5, no. 5-6, pp. 497-519, 2003.

[18] G. I. Dzhardimalieva, A. D. Pomogailo, A. S. Rozenberg, and M. Leonowicz, "Magnetic metallopolymer nanocomposites," in Magnetic Nanoparticles, S. P. Gubin, Ed., chapter 3, Wiley, 2009. 
[19] V. S. Savostyanov, V. I. Ponomarev, A. D. Pomogailo et al., "Preparation and reactivity of metal-containing monomers," Bulletin of the Academy of Sciences of the USSR, vol. 39, no. 4, pp. 674-679, 1990.

[20] A. D. Pomogailo and G. I. Dzhardimalieva, "Frontal polymerization of metal-containing monomers: achievements and problems," Polymer Science A, vol. 46, no. 3, pp. 250-263, 2004.

[21] T. Shi and L. I. Elding, "Kinetics and mechanism for formation of olefin complexes in the reaction between palladium(II) and maleic acid," Inorganic Chemistry, vol. 37, no. 21, pp. 5544-5549, 1998.

[22] G. I. Dzhardimalieva, A. D. Pomogailo, and V. A. Volpert, "Frontal polymerization of metal-containing monomers: a topical review," Journal of Inorganic and Organometallic Polymers, vol. 12, no. 1-2, pp. 1-21, 2002.

[23] K. Okitsu, A. Yue, S. Tunabe, and H. Matsumoto, "Formation of palladium nanoclusters on Y-zeolite via a sonochemical process and conventional methods," Bulletin of the Chemical Society of Japan, vol. 75, no. 3, pp. 449-455, 2002.

[24] D. I. Fortenberry and J. A. Pojman, "Solvent-free synthesis of polyacrylamide by frontal polymerization," Journal of Polymer Science A, vol. 38, no. 7, pp. 1129-1135, 2000.

[25] V. V. Barelko, A. D. Pomogailo, G. I. Dzhardimalieva, S. I. Evstratova, A. S. Rozenberg, and I. E. Uflyand, “The autowave modes of solid phase polymerization of metal-containing monomers in two- and three-dimensional fiberglass-filled matrices," Chaos, vol. 9, no. 2, pp. 342-347, 1999.

[26] S. I. Pomogailo, V. G. Dorokhov, A. M. Lyakhovich, S. S. Mikhailova, G. I. Dzhardimalieva, and A. D. Pomogailo, "Synthesis, structure, and catalytic properties of polymerimmobilized rhodium clusters," Kinetics and Catalysis, vol. 47, no. 5, pp. 719-727, 2006.

[27] S. Kidambi, J. Dai, J. Li, and M. L. Bruening, "Selective hydrogenation by $\mathrm{Pd}$ nanoparticles embedded in polyelectrolyte multilayers," Journal of the American Chemical Society, vol. 126, no. 9, pp. 2658-2659, 2004.

[28] Y. Jiang and Q. Gao, "Heterogeneous hydrogenation catalyses over recyclable $\operatorname{Pd}(0)$ nanoparticle catalysts stabilized by PAMAM-SBA-15 organic-inorganic hybrid composites," Journal of the American Chemical Society, vol. 128, no. 3, pp. 716-717, 2006.

[29] E. F. Litvin and V. Z. Sharf, "Catalytic hydrogenation of trinitrotoluene," Mendeleev Chemistry Journal, vol. 44, p. 90, 2000.

[30] H. J. Janssen, A. J. Kruithof, G. J. Steghuis, and K. R. Westerterp, "Kinetics of the catalytic hydrogenation of 2,4-dinitrotoluene. 2. Modeling of the reaction rates and catalyst activity," Industrial \& Engineering Chemistry Research, vol. 29, no. 9, pp. 1822-1829, 1990.

[31] G. Neri, M. G. Musolino, C. Milone, A. M. Visco, and A. Di Mario, "Mechanism of 2,4-dinitrotoluene hydrogenation over Pd/C," Journal of Molecular Catalysis A, vol. 95, no. 3, pp. 235-241, 1995.

[32] W. Chuntiag, V. G. Dorokhov, G. A. Boiko, B. S. Bal'zhinimaev, and V. V. Barelko, "Characteristic features of the selective action of platinum-doped glass fiber woven catalysts in the liquid-phase reduction of polyfunctional aromatic nitro compounds," Doklady Chemistry, vol. 402, no. 4-6, pp. 111-113, 2005. 

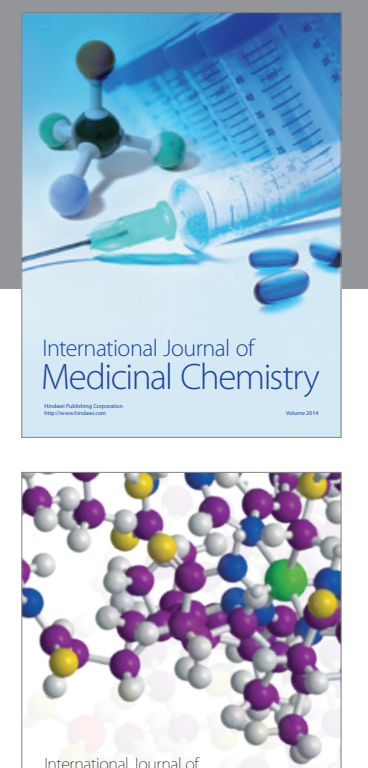

\section{Carbohydrate} Chemistry

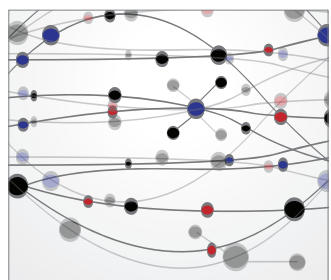

The Scientific World Journal
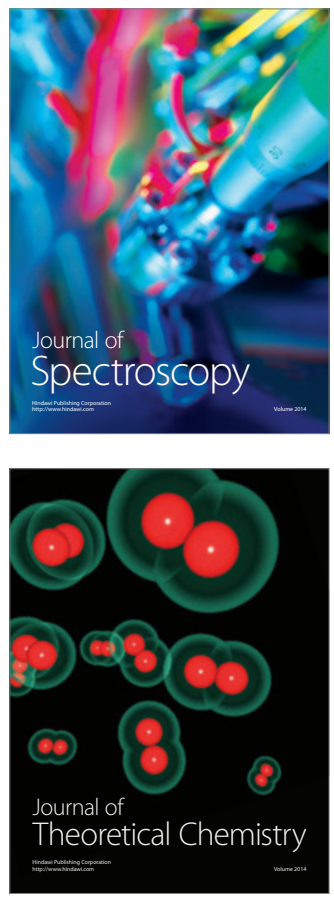
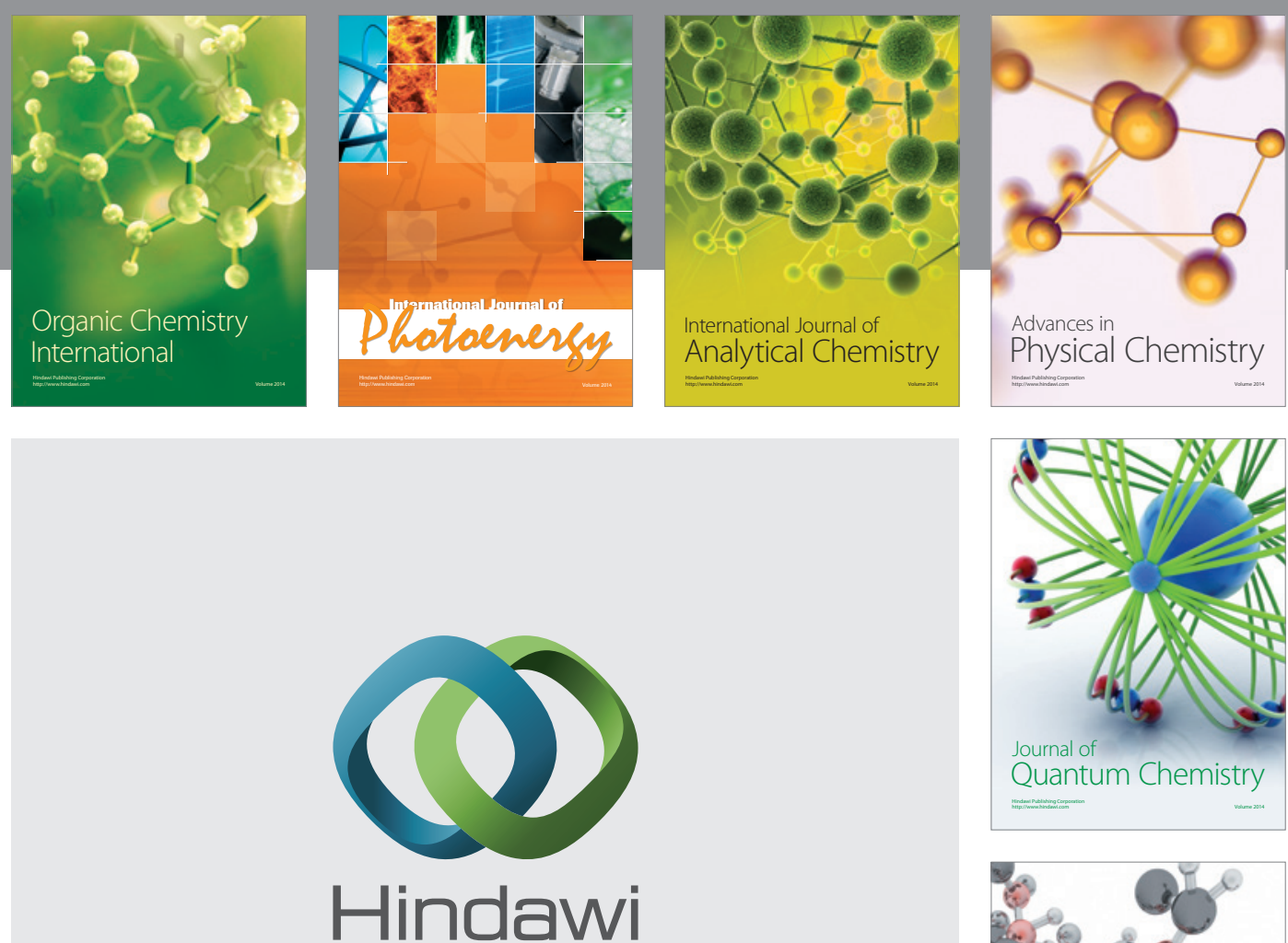

Submit your manuscripts at

http://www.hindawi.com

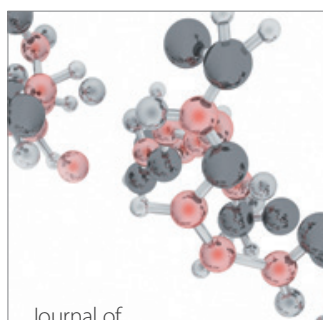

Analytical Methods

in Chemistry

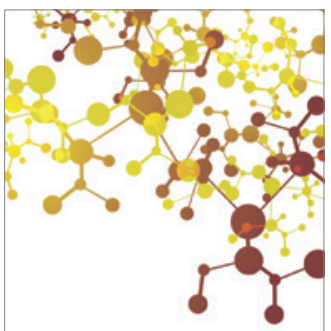

Journal of

Applied Chemistry

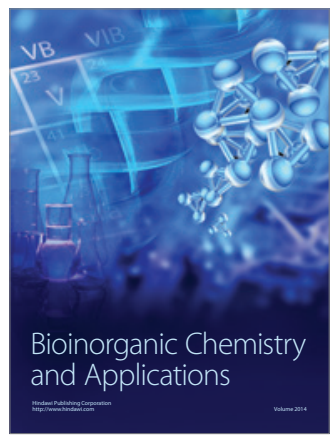

Inorganic Chemistry
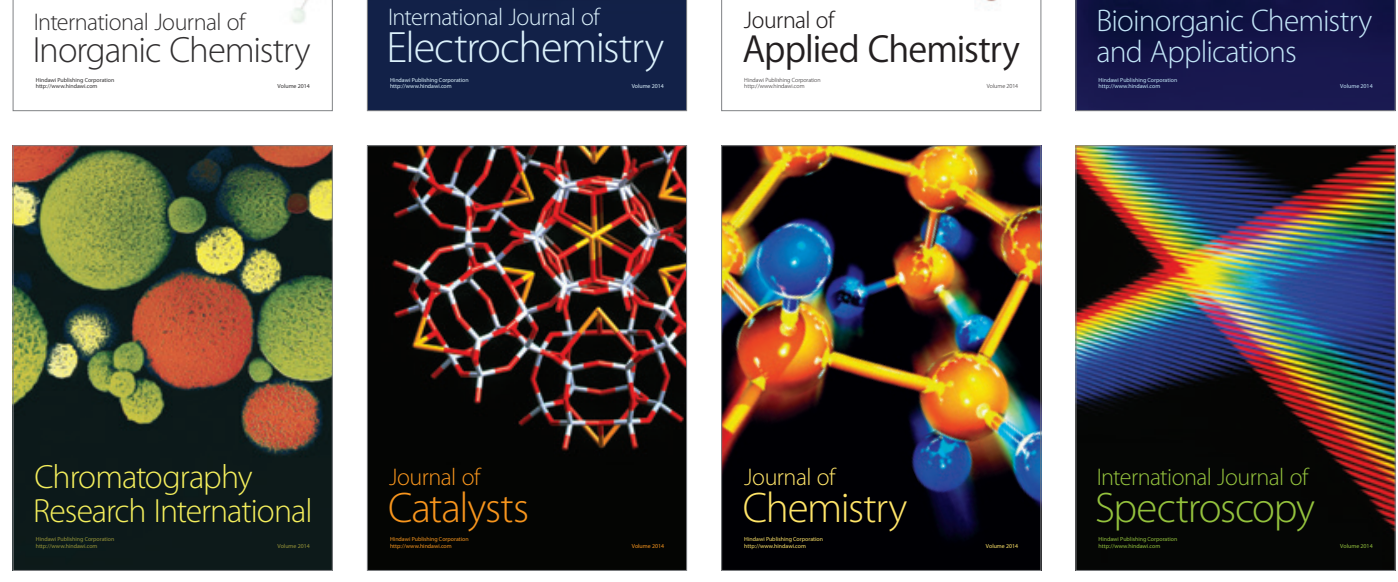